\title{
Mechanochemical synthesis of $\mathrm{ZrB}_{2}-\mathrm{SiC}-\mathrm{ZrC}$ nanocomposite powder by metallothermic reduction of zircon
}

\author{
M. Jalaly ${ }^{1, *}$, M. Tamizifar $^{1}$, M.Sh. Bafghi ${ }^{1}$, F.J. Gotor ${ }^{2}$ \\ 1. School of Metallurgy and Materials Engineering, Iran University of Science \& Technology \\ (IUST), Narmak, Tehran 16846-13114, Iran \\ 2. Instituto de Ciencia de Materiales de Sevilla (CSIC-US), Americo Vespucio 49, 41092 \\ Sevilla, Spain \\ *Corresponding Author, Email: maisam_jalaly@iust.ac.ir \\ Tel: +989127387902, Fax: +982177240480
}

\begin{abstract}
Aluminium and magnesium were used in the $\mathrm{M} / \mathrm{ZrSiO}_{4} / \mathrm{B}_{2} \mathrm{O}_{3} / \mathrm{C}(\mathrm{M}=\mathrm{Al}, \mathrm{Mg})$ system to induce a mechanically induced self-sustaining reaction (MSR). Aluminium was not able to reduce the system to the desired products, and the system became amorphous after 10 hours milling. However, Nanocomposite powder of $\mathrm{ZrB}_{2}-\mathrm{SiC}-\mathrm{ZrC}$ was in-situ synthesized by the magnesiothermic reduction with an ignition time of approximately 6 minutes. The mechanism for the formation of the product in this system was determined by studying the relevant sub-reactions.
\end{abstract}

Keywords: Zirconium diboride; Mechanosynthesis; Zircon;

\section{Introduction}

$\mathrm{ZrB}_{2}$, as one of the most important materials among the so-called Ultra-High Temperature Ceramics (UHTCs), has excellent properties such as high melting point, high hardness and strength at room and elevated temperatures, good thermal and 
electrical conductivities, low thermal expansion coefficient, chemical inertness, good oxidation resistance, and high thermal stability [1].

$\mathrm{ZrB}_{2}$ based ceramics have attracted much attention especially in the areas where wear-corrosion-oxidation resistance is demanded; such as high temperature electrodes, molten metal crucibles, thermal protection systems for hypersonic flights, atmospheric re-entry vehicles, rocket propulsion systems, and nose caps [2-4]. However, $\mathrm{ZrB}_{2}$ is not only difficult to sinter, but also by itself does not meet all the necessary requirements demanded by the extreme conditions encountered in the aerospace engineering $[5,6]$. Consequently, $\mathrm{ZrB}_{2}$ is usually employed in combination with other refractory ceramics. $\mathrm{SiC}$ is one of the most widely used materials for making applicable composites with $\mathrm{ZrB}_{2}$ [7-10]. This is because $\mathrm{SiC}$ can improve sinterability, oxidation resistance, and mechanical properties of zirconium diboride. $\mathrm{ZrC}$ is another suitable material which can be added to $\mathrm{ZrB}_{2}$ as a sintering aid as well as a reinforcement. Tsuchida and Yamamoto [11] synthesized $\mathrm{ZrB}_{2}-\mathrm{ZrC}$ composite by mechanically activated self-propagating high temperature synthesis ( $\mathrm{SHS}$ ) in a $\mathrm{Zr} / \mathrm{B} / \mathrm{C}$ elemental system. $\mathrm{ZrB}_{2}-\mathrm{SiC}-\mathrm{ZrC}$ composites have also been developed by a number of researchers through various methods such as spark plasma sintering of blended materials $[12,13]$, inducing reaction in the $\mathrm{Zr} / \mathrm{Si} / \mathrm{B}_{4} \mathrm{C}$ system during heating followed by hot pressing [14], and reactive hot pressing in the $\mathrm{Zr} / \mathrm{Si} / \mathrm{B}_{4} \mathrm{C}$ system [15].

When an SHS reaction is induced by the high-energy ball milling of reactants after a critical milling period, called the ignition time, such a mechanochemical process is referred to as the mechanically induced self-sustaining reaction (MSR). In contrast to the conventional SHS procedure, the MSR process has the side benefit of performing the followings in a single step: the mixing of the reactants, the subsequent 
homogenization of the products, and the extreme particle size reduction of both reactants and products.

Literature survey shows a great attention to the metallothermic reduction of $\mathrm{ZrO}_{2}$ and $\mathrm{B}_{2} \mathrm{O}_{3}$ for the preparation of $\mathrm{ZrB}_{2}$, because of using cheaper raw materials as well as taking advantage of the high exothermic nature of the involving self-sustaining reactions compared to the other synthesis routes [16-21].

Zircon $\left(\mathrm{ZrSiO}_{4}\right)$, as a joint source of zirconium and silicon, can be employed for the synthesis of $\mathrm{ZrB}_{2}-\mathrm{SiC}$-based composites, which has not been significantly used so far. The aim of the present work was to investigate the preparation of $\mathrm{ZrB}_{2}-\mathrm{SiC}-\mathrm{ZrC}$ composite powder by using $\mathrm{ZrSiO}_{4}, \mathrm{~B}_{2} \mathrm{O}_{3}$, and graphite as the starting materials and aluminum and magnesium as the reducing agents, by means of a mechanically induced self-sustaining reaction (MSR).

\section{Experimental}

$\mathrm{ZrSiO}_{4}\left(98 \%\right.$, Alfa-Aesar, USA), $\mathrm{B}_{2} \mathrm{O}_{3}$ (98\%, Fluka, USA), graphite (99\%, Fluka, USA), Al (99\%, Aldrich, USA) and Mg (99\%, Riedel-deHaen, Germany) powders were used as starting materials to prepare the target products. Initial materials were subjected to the high-energy ball milling in a modified planetary ball mill (Pulverisette7, Fritsch, Germany). The rotational speed and ball-to-powder mass ratio were $600 \mathrm{rpm}$ and 30:1, respectively. The milling vial and balls $(15 \mathrm{~mm})$ were made of hardened chromium steel. All milling experiments were conducted under 5 bar of high-purity argon gas. The vial was purged with argon gas several times, and the desired pressure was adjusted before the start of the milling. The connection of the vial to the gas cylinder was maintained during the milling experiments by a rotating union and a flexible polyamide tube. The pressure change versus time was monitored by a SMC solenoid valve (model 
EVT307-5DO-01F-Q, SMC Co,. Tokyo, Japan) to record the ignition time. A sharp peak due to the pressure rise appears when an MSR reaction occurs. The position of this peak shows the ignition time. The system used in this work has already been illustrated elsewhere [22]. Magnesium oxide by-product was removed by leaching the as-milled powder in a $1 \mathrm{M}-\mathrm{HCl}$ solution at $80^{\circ} \mathrm{C}$ for $1 \mathrm{~h}$.

Structural features of the samples were investigated using X-ray powder diffraction (XRD) analysis by means of a PANalitycal X'Pert diffractometer $(45 \mathrm{kV}, 40$ $\mathrm{mA}$ ) with $\mathrm{Cu} \mathrm{K} \alpha$ radiation $(\lambda=0.15406 \mathrm{~nm})$. Scanning electron microscopy (SEM) images were obtained by a Hitachi S-4800 SEM-Field Emission Gun microscope. Transmission electron microscopy (TEM) images were taken using a $200 \mathrm{kV}$ Philips CM200 microscope equipped with a SuperTwin objective lens and a tungsten filament (point resolution $\varnothing=0.25 \mathrm{~nm}$ ). Powdered samples were dispersed in ethanol, and droplets of the suspension were deposited onto a holey carbon film.

\section{Results and Discussion}

\subsection{Aluminothermic reduction}

If aluminum is selected as the metallic reducing agent, the main reaction is as follows:

$\mathrm{ZrSiO}_{4}+\mathrm{B}_{2} \mathrm{O}_{3}+\mathrm{C}+(14 / 3) \mathrm{Al} \rightarrow \mathrm{ZrB}_{2}+\mathrm{SiC}+(7 / 3) \mathrm{Al}_{2} \mathrm{O}_{3}$

$\Delta \mathrm{G}_{298}^{\circ}=-975 \mathrm{~kJ} / \mathrm{mol}, \Delta \mathrm{H}_{298}^{\circ}=-1005 \mathrm{~kJ} / \mathrm{mol}, \mathrm{T}_{\mathrm{ad}} \approx 2320 \mathrm{~K}$

Above reaction has suitable thermodynamic criteria to exhibit an SHS behavior. However, no change in the internal pressure of the vial was observed during a long-term milling. Fig. 1 shows the XRD patterns of initial powder mixture of this system together with those of the samples milled for different time periods. In contrast to the thermodynamic expectation, it can be seen that the desired reaction did not occur even 
after $10 \mathrm{~h}$ milling. Peak broadening and reduction of peak intensities were only observations which are the signs of amorphization of the initial constituents. After $10 \mathrm{~h}$

milling, powder mixture became almost completely amorphous and slight amounts of $\mathrm{AlB}_{2}$ as the major crystalline phase were formed by the reaction between slightly reduced boron and present aluminum. Notwithstanding the necessary thermodynamic conditions for the reaction (1) are fulfilled, this system appears to have a kinetic obstacle to proceed. In other words, aluminum does not have adequate reducibility to overcome the required activation energy of the system. Furthermore, the applied energy by the ball impacts in the current conditions has not been sufficiently high to prevail the energy barrier. Thus, materials subjected to the impacts during long-term milling become amorphous rather than the occurrence of the reaction. A slight amount of boron was obtained during long milling time by the successive ball impacts which found the chance to react with present $\mathrm{Al}$ to form aluminum diboride.

SEM and TEM images of sample milled for $10 \mathrm{~h}$ are shown in Fig.2. Since the reaction did not occur and sample went toward the amorphous form, SEM micrograph shows sample to be in the form of large granules which have been heavily stuck to each other, because of a long-term milling period. TEM micrograph shows sample in a high magnification. No crystalline particles can be observed in the microstructural image, corroborating the amorphous nature of the $10 \mathrm{~h}$-milled powder.

\subsection{Magnesiothermic reduction}

Because aluminium did not succeed to reduce the system, magnesium was selected as the reducing agent due to its more reducibility. The overall reaction was considered as the following equation:

$\mathrm{ZrSiO}_{4}+\mathrm{B}_{2} \mathrm{O}_{3}+\mathrm{C}+7 \mathrm{Mg} \rightarrow \mathrm{ZrB}_{2}+\mathrm{SiC}+7 \mathrm{MgO}$ 
$\Delta \mathrm{G}_{298}^{\circ}=-1270 \mathrm{~kJ} / \mathrm{mol}, \Delta \mathrm{H}_{298}^{\circ}=-1300 \mathrm{~kJ} / \mathrm{mol}, \mathrm{T}_{\mathrm{ad}} \approx 2750 \mathrm{~K}$

Above reaction also is highly exothermic with a very high adiabatic temperature $\left(\mathrm{T}_{\mathrm{ad}}\right)$ which implies that the reaction can proceed in an SHS mode [23]. Stoichiometric amounts of the starting materials were milled under the conditions mentioned earlier. The change of internal pressure of the vial versus milling time is shown in Fig. 3. A large pressure rise was observed during milling, confirming the occurrence of a severe exothermic reaction after a short ignition time of 6 min.

Fig. 4 shows the XRD patterns of $\mathrm{ZrSiO}_{4}, \mathrm{~B}_{2} \mathrm{O}_{3}, \mathrm{C}$, and $\mathrm{Mg}$ powder mixture asblended and after different milling times. The XRD pattern of as-blended mixture included only the peaks of $\mathrm{Mg}$ (ICCD PDF \#35-0821), $\mathrm{ZrSiO}_{4}$ (ICCD PDF \#06-0266), $\mathrm{B}_{2} \mathrm{O}_{3}$ (ICCD PDF \#06-0297), and graphite (ICCD PDF \#08-0415). The products after the ignition point at 6 min included $\mathrm{ZrB}_{2}$ (ICCD PDF \#34-0423) as the major phase, MgO (ICCD PDF \#04-0829), SiC (ICCD PDF \#29-1131), and ZrC (ICCD PDF \#191487). A small amount of zircon remained just after ignition, which is a typical behavior of the MSR reactions [23] with short ignition times, due to the insufficient mixing of the reactants at short time together with the entrapment of some powders in the dead zones of the milling vial. By increasing the milling time, unreacted and/or trapped powders can be gradually subjected to the ball impacts and locally reacted. Fig. 4 shows the XRD pattern of a sample milled for 3 hours in which zircon phase was entirely disappeared. Dissolution of magnesium oxide was carried out using a $1 \mathrm{M}-\mathrm{HCl}$ solution. The XRD pattern of the leached sample after $3 \mathrm{~h}$ milling is also shown in Fig. 4. It can be observed that $\mathrm{MgO}$ was completely removed and the remaining product is a composite of $\mathrm{ZrB}_{2}-\mathrm{SiC}-\mathrm{ZrC}$. 
According to the reaction (2), $\mathrm{ZrC}$ is not expected to be present among the products, but as seen in Fig.2, it is an inevitable (but valuable) by-product in this system. The formation of $\mathrm{ZrC}$ can be explained by the following reaction mechanism. At the ignition point, magnesium reduces boron oxide and zircon to yield elemental boron, silicon, and zirconium. Therefore, $\mathrm{Si}, \mathrm{Zr}, \mathrm{B}$, and $\mathrm{C}$ elements are now present in the system. Fig.5 shows the standard free energy of the formation of various possible compounds containing these elements. It is clear that $\mathrm{ZrB}_{2}$ has the most negative free energy value; hence, boron has the greatest tendency to react with zirconium to form zirconium diboride. The stability diagram exhibits that $\mathrm{ZrC}$ has a fairly high tendency of formation in comparison to the other compounds. Therefore, the formation of a small amount of zirconium carbide through the reaction between zirconium and carbon, appears to be inevitable. Concurrent formation of $\mathrm{ZrB}_{2}$ and $\mathrm{ZrC}$ has also been reported by other researchers [24]. Afterwards, the reduced silicon and remained carbon can form $\mathrm{SiC}$ as the second carbide phase. The different sub-reactions occurring at the ignition moment can be written as follows:

$\mathrm{B}_{2} \mathrm{O}_{3}+3 \mathrm{Mg} \rightarrow 2 \mathrm{~B}+3 \mathrm{MgO}$

$\mathrm{ZrSiO}_{4}+4 \mathrm{Mg} \rightarrow \mathrm{Zr}+\mathrm{Si}+4 \mathrm{MgO}$

$\mathrm{Zr}+2 \mathrm{~B} \rightarrow \mathrm{ZrB}_{2}$

$\mathrm{Zr}+\mathrm{C} \rightarrow \mathrm{ZrC}$

$\mathrm{Si}+\mathrm{C} \rightarrow \mathrm{SiC}$

All these steps occur instantaneously, as shown in Figs.3 and 4. In this mechanism, it should be elucidated whether the ignition occurred in the overall selfsustaining reaction is induced by the reaction between $\mathrm{Mg}$ and $\mathrm{B}_{2} \mathrm{O}_{3}$ or the reaction 
between $\mathrm{Mg}$ and $\mathrm{ZrSiO}_{4}$. For this purpose, two reactions were separately studied in the MSR experiments:

$3 \mathrm{Mg}+\mathrm{B}_{2} \mathrm{O}_{3} \rightarrow 2 \mathrm{~B}+3 \mathrm{MgO}$

$\Delta \mathrm{G}_{298}^{\circ}=-515 \mathrm{~kJ}, \Delta \mathrm{H}^{\circ}{ }_{298}=-532 \mathrm{~kJ}, \mathrm{~T}_{\mathrm{ad}} \approx 2630 \mathrm{~K}$

$4 \mathrm{Mg}+\mathrm{ZrSiO}_{4} \rightarrow \mathrm{Zr}+\mathrm{Si}+4 \mathrm{MgO}$

$\Delta \mathrm{G}_{298}^{\circ}=-363 \mathrm{~kJ}, \Delta \mathrm{H}^{\circ}{ }_{298}=-368 \mathrm{~kJ}, \mathrm{~T}_{\mathrm{ad}} \approx 1680 \mathrm{~K}$

The reaction between magnesium and boron oxide is observed to meet necessary thermodynamic criteria required for an SHS reaction. On the other side, adiabatic temperature of the reaction between magnesium and zircon is below the Merzhanov criterion $(1800 \mathrm{~K})$ [23]. Stoichiometric amounts of starting materials in the $\mathrm{Mg} / \mathrm{B}_{2} \mathrm{O}_{3}$ and $\mathrm{Mg} / \mathrm{ZrSiO}_{4}$ systems were separately mixed according to the reactions (3) and (4) and milled under the similar conditions. In the case of reaction (3), the MSR reaction occurred and the ignition time was found to be about 8 min (Fig. 6). The XRD patterns of initial materials alongside with a sample milled up to the ignition point $(8 \mathrm{~min})$ are shown in Fig. 7. It can be seen that the ignited sample contained magnesium oxide together with a small amount of the unreacted starting magnesium due to the reasons stated previously. Elemental boron cannot be observed in the pattern, most likely due to its amorphous state because of the extremely high heating and cooling rates at the ignition point. A small amount of an $\mathrm{MgO}$-rich spinel $\left(3 \mathrm{MgO} \cdot \mathrm{B}_{2} \mathrm{O}_{3}\right)$ was also formed after the ignition. The formation of this spinel phase can be explained as a consequence of the reaction between $\mathrm{MgO}$ as the reaction product and remaining boron oxide.

For reaction (4), as expected from thermodynamic prediction, no pressure rise was observed throughout the milling time. Fig. 8 shows the XRD pattern of un-milled powder together with that of sample milled up to $4 \mathrm{~h}$ in this system. Only peak 
broadening is observable, with no sign of the occurrence of any reaction during this long milling time. This indicates that during milling under the applied conditions, $\mathrm{Mg}$ cannot reduce zircon in an SHS manner. This reaction might happen in an ordinary way under more intensive experimental conditions for a much longer time.

It is, therefore, demonstrated that during milling of $\mathrm{Mg}, \mathrm{B}_{2} \mathrm{O}_{3}$, and $\mathrm{ZrSiO}_{4}$ mixture, magnesium reduces boron oxide in a self-sustaining manner to yield elemental boron and magnesia together with the generation of a significant amount of heat. This giant value of heat increases the temperature inside the milling vial to a level that can initiate the reaction between $\mathrm{Mg}$ and zircon to form elemental $\mathrm{Zr}$ and $\mathrm{Si}$, and also more magnesia. As a result, $\mathrm{ZrB}_{2}, \mathrm{ZrC}$, and $\mathrm{SiC}$ are obtained by the reaction between the reduced elements and carbon. The highly exothermic reactions of the formation of these refractory compounds add an extra amount of heat to the system, and for this reason, the ignition time of the overall reaction is slightly shortened as compared to the $\mathrm{Mg} / \mathrm{B}_{2} \mathrm{O}_{3}$ system. As previously mentioned, all these different steps occur simultaneously.

The electron microgarphs of a sample milled for $3 \mathrm{~h}$ are shown in Fig. 9. As SEM micrograph shows, the micrometric agglomerates are observed to contain submicrometric and nanometric particles with semi-spherical morphologies. TEM micrograph in Fig. 9 (b) shows a nanoparticle of hexagonal $\mathrm{ZrB}_{2}$ single crystal ( 110 $\mathrm{nm}$ in diameter) surrounded by $\mathrm{MgO}$ nanoparticles.

\section{Conclusions}

High energy ball milling technique was successfully applied for the mechanosynthesis of $\mathrm{ZrB}_{2}-\mathrm{SiC}-\mathrm{ZrC}$ composite by means of the magnesiothermic reduction in the $\mathrm{Mg} / \mathrm{B}_{2} \mathrm{O}_{3} / \mathrm{ZrSiO}_{4} / \mathrm{C}$ system. It was found that the mechanochemical process possesses an SHS nature having an ignition time of $6 \mathrm{~min}$. Examination of the sub-reactions 
revealed that boron oxide is easily reduced by $\mathrm{Mg}$, while magnesium cannot reduce $\mathrm{ZrSiO}_{4}$ to $\mathrm{Zr}$ and $\mathrm{Si}$ in an SHS manner. It was concluded that the great deal of heat generated through the reduction of boron oxide by $\mathrm{Mg}$ is capable of stimulating the reduction of $\mathrm{ZrSiO}_{4}$. It was found that in spite of the thermodynamic possibility, no tangible reduction was observed in $\mathrm{Al} / \mathrm{B}_{2} \mathrm{O}_{3} / \mathrm{ZrSiO}_{4} / \mathrm{C}$ system, likely due to the high value of activation energy which could not be overwhelmed under the current experimental conditions. This system was approximately amorphous after $10 \mathrm{~h}$ milling including negligible amounts of $\mathrm{AlB}_{2}$.

\section{Acknowledgements}

This work was financially supported by the Spanish government under grant No. MAT2011-22981, which was financed in part by the European Regional Development Fund of 2007-2013. The work has been based on an initiation proposed by the School of Metallurgy and Materials Engineering of the Iran university of science and technology as the $\mathrm{Ph} . \mathrm{D}$ thesis subject of Mr. M. Jalaly who was granted the permission to accomplish his experiments with the facilities and co-supervision of Prof. F.J. Gotor in Instituto de Ciencia de Materiales de Sevilla, Sevilla, Spain.

\section{References}

[1] M.A. Aviles, J.M. Cordoba, M.J. Sayagues, M.D. Alcala, F.J. Gotor, Mechanosynthesis of $\mathrm{Hf}_{1-\mathrm{x}} \mathrm{Zr}_{\mathrm{x}} \mathrm{B}_{2}$ Solid Solution and $\mathrm{Hf}_{1-\mathrm{x}} \mathrm{Zr}_{\mathrm{x}} \mathrm{B}_{2} / \mathrm{SiC}$ Composite Powders, Journal of the American Ceramic Society 93 (2010) 696-702.

[2] A.L. Chamberlain, W.G. Fahrenholtz, G.E. Hilmas, High-Strength Zirconium DiborideBased Ceramics, Journal of the American Ceramic Society 87 (2004) 1170-1172.

[3] M. Brochu, B.D. Gauntt, L. Boyera, R.E. Loehman, Pressureless reactive sintering of $\mathrm{ZrB}_{2}$ ceramic, Journal of the European Ceramic Society 29 (2009) 1493-1499. 
[4] J.J. Melendez-Martinez, A. Dominguez-Rodriguez, F. Monteverde, C. Melandri, G. de Portu, Characterization and high temperature mechanical properties of zirconium boride-based materials, Journal of the European Ceramic Society 22 (2002) 2543-2549.

[5] W.G. Fahrenholtz, G.E. Hilmas, I.G. Talmy, J.A. Zaykoski, Refractory diborides of zirconium and hafnium, Journal of the American Ceramic Society 90 (2007) 1347-1364.

[6] S.Q. Guo, Densification of $\mathrm{ZrB}_{2}$-based composites and their mechanical and physical properties: A review, Journal of the European Ceramic Society 29 (2009) 995-1011.

[7] S.Q. Guo, J.M. Yang, H. Tanaka, Y. Kagawa, Effect of thermal exposure on strength of $\mathrm{ZrB}_{2}$-based composites with nano-sized $\mathrm{SiC}$ particles, Composites Science and Technology 68 (2008) 3033-3040.

[8] F. Monteverde, Beneficial effects of an ultra-fine $\alpha$-SiC incorporation on the sinterability and mechanical properties of $\mathrm{ZrB}_{2}$, Applied Physics A -Materials Science \& Processing 82 (2006) 329-337.

[9] H. Zhang, Y. Yan, Z. Huang, X. Liu, D. Jiang, Properties of ZrB2-SiC Ceramics by Pressureless Sintering, Journal of the American Ceramic Society 92 (2009) 1599-1602.

[10] P. Hu, W. Guolin, Z. Wang, Oxidation mechanism and resistance of $\mathrm{ZrB}_{2}-\mathrm{SiC}$ composites, Corrosion Science 51 (2009) 2724-2732.

[11] T. Tsuchida, S. Yamamoto, MA-SHS and SPS of $\mathrm{ZrB}_{2}-\mathrm{ZrC}$ composites, Solid State Ionics 172 (2004) 215-216.

[12] S.Q. Guo, Y. Kagawa, T. Nishimura, D. Chung, J.M. Yang, Mechanical and physical behavior of spark plasma sintered $\mathrm{ZrC}-\mathrm{ZrB}_{2}-\mathrm{SiC}$ composites, Journal of the European Ceramic Society 28 (2008) 1279-1285.

[13] A. Snyder, D. Quach, J.R. Groza, T. Fisher, S. Hodson, L.A. Stanciu, Spark Plasma Sintering of $\mathrm{ZrB}_{2}-\mathrm{SiC}-\mathrm{ZrC}$ ultra-high temperature ceramics at $1800^{\circ} \mathrm{C}$, Materials Science and Engineering A 528 (2011) 6079-6082. 
[14] Q. Qiang, H. Jiecai, H. Wenbo, Z. Xinghong, H. Changqing, In situ synthesis mechanism and characterization of $\mathrm{ZrB}_{2}-\mathrm{ZrC}-\mathrm{SiC}$ ultra high-temperature ceramics, Materials Chemistry and Physics 110 (2008) 216-221.

[15] W.W. Wu, G.J. Zhang, Y.M. Kan, P.L. Wang, Reactive Hot Pressing of $\mathrm{ZrB}_{2}-\mathrm{SiC}-\mathrm{ZrC}$ Composites at $1600^{\circ} \mathrm{C}$, Journal of the American Ceramic Society 91 (2008) 2501-2508.

[16] A.K. Khanra, L.C. Pathak, S.K. Mishra, M.M. Godkhindi, Sintering of ultrafine zirconium diboride powder prepared by modified SHS technique, Advances in Applied Ceramics 104 (2005) 282-284.

[17] K. Nishiyama, T. Nakamur, S. Utsumi, H. Sakai, M. Abe, Preparation of ultrafine boride powders by metallothermic reduction method, Journal of Physics: Conference Series 176 (2009) 012043.

[18] N. Setoudeh, N.J. Welham, Formation of zirconium diboride $\left(\mathrm{ZrB}_{2}\right)$ by room temperature mechanochemical reaction between $\mathrm{ZrO}_{2}, \mathrm{~B}_{2} \mathrm{O}_{3}$ and $\mathrm{Mg}$, Journal of Alloys and Compounds 420 (2006) 225-228.

[19] S.K. Mishra, S. Das, L.C. Pathak, Defect structures in zirconium diboride powder prepared by self-propagating high-temperature synthesis, Materials Science and Engineering A364 (2004) 249-255.

[20] B. Akgun, H.E. Camurlu, Y. Topkaya, N. Sevinc, Mechanochemical and volume combustion synthesis of $\mathrm{ZrB}_{2}$, International Journal of Refractory Metals and Hard Materials 29 (2011) 601-607.

[21] Y.B. Lee, H.C. Park, K.D. Oh, C.R. Bowen, R. Stevens, Self-propagating high-temperature synthesis of $\mathrm{ZrB}_{2}$ in the system $\mathrm{ZrO}_{2}-\mathrm{B}_{2} \mathrm{O}_{3}-\mathrm{Fe}_{2} \mathrm{O}_{3}-\mathrm{Al}$, Journal of Materials Science Letters 19 (2000) 469-471.

[22] F.J. Gotor, M. Achimovicova, C. Real, P. Balaz, Influence of the milling parameters on the mechanical work intensity in planetary mills, Powder Technology 233 (2013) 1-7. 
[23] L. Takacs, Self-sustaining reactions induced by ball milling, Progress in Materials Science 47 (2002) 355-414.

[24] H. Y. Ryu, H.H. Nersisyan, J.H. Lee, Preparation of zirconium-based ceramic and composite fine-grained powders, International Journal of Refractory Metals and Hard Materials 30 (2012) 133-138.

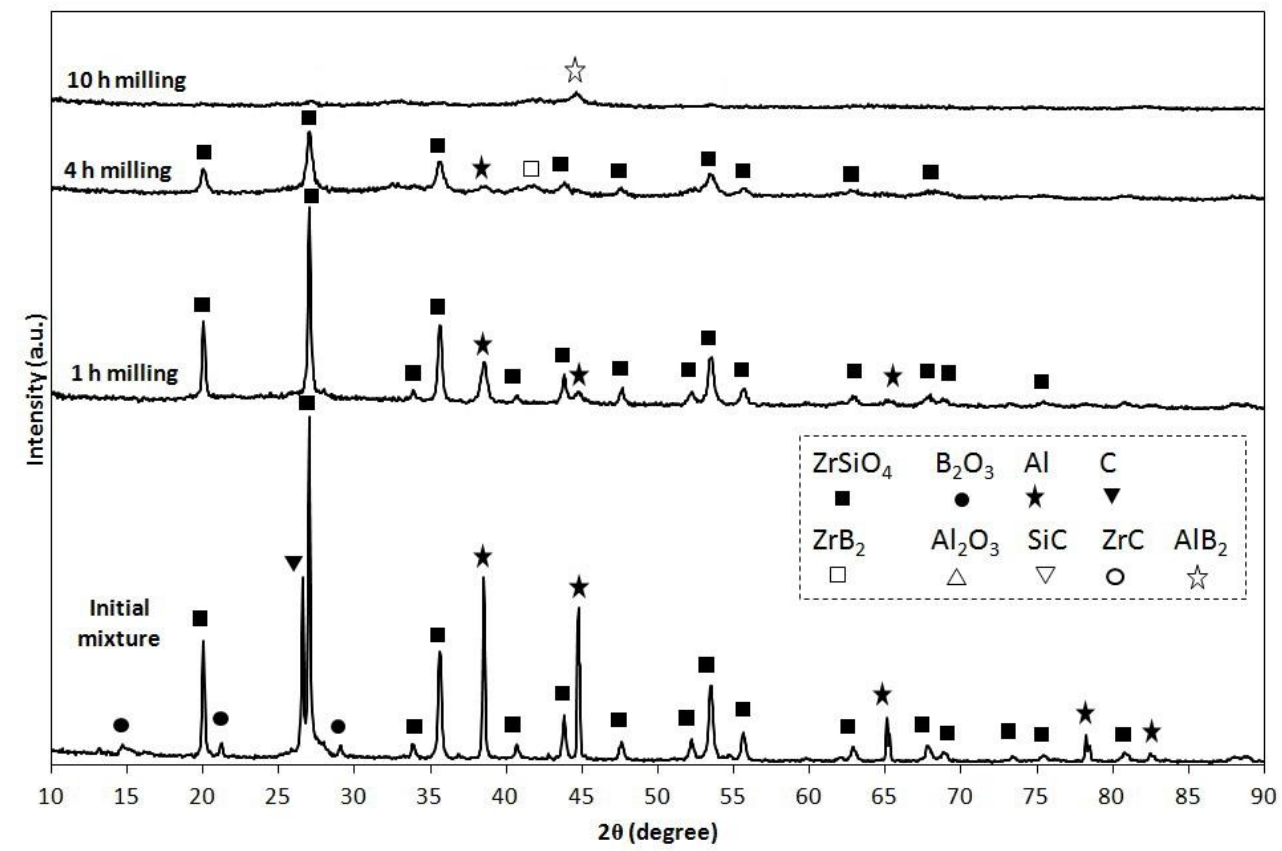

Fig. 1. X-ray diffraction patterns of as-blended and milled samples of $\mathrm{Al} / \mathrm{ZrSiO}_{4} / \mathrm{B}_{2} \mathrm{O}_{3} / \mathrm{C}$ system. 

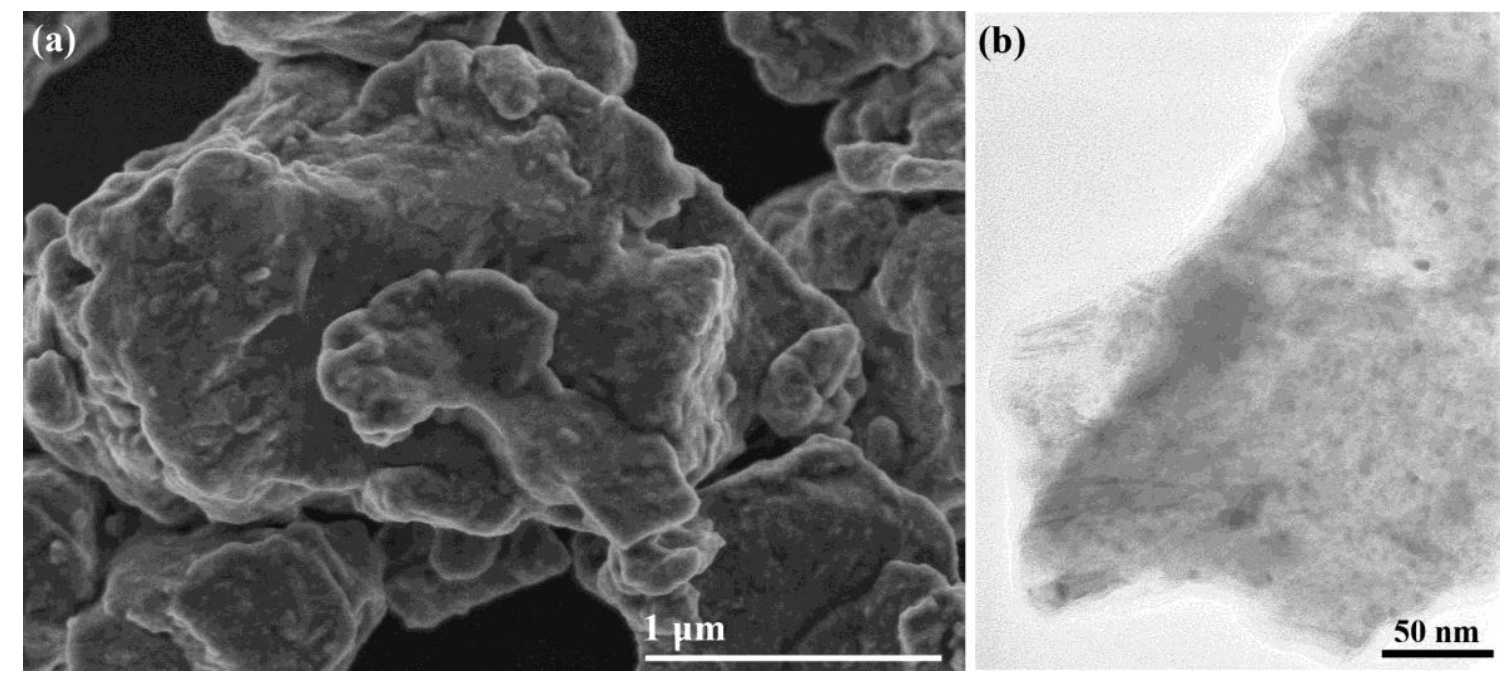

Fig. 2. Electron micrographs of $\mathrm{Al} / \mathrm{ZrSiO}_{4} / \mathrm{B}_{2} \mathrm{O}_{3} / \mathrm{C}$ system after $3 \mathrm{~h}$ milling, (a) SEM and (b) TEM images.

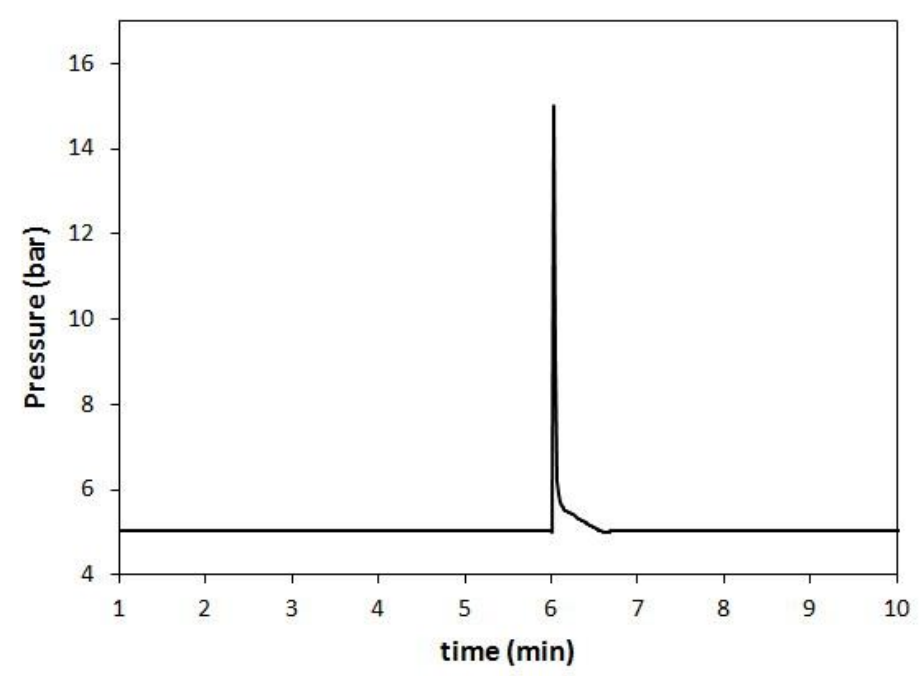

Fig. 3. Pressure inside the vial versus milling time for $\mathrm{Mg} / \mathrm{ZrSiO}_{4} / \mathrm{B}_{2} \mathrm{O}_{3} / \mathrm{C}$ system. 


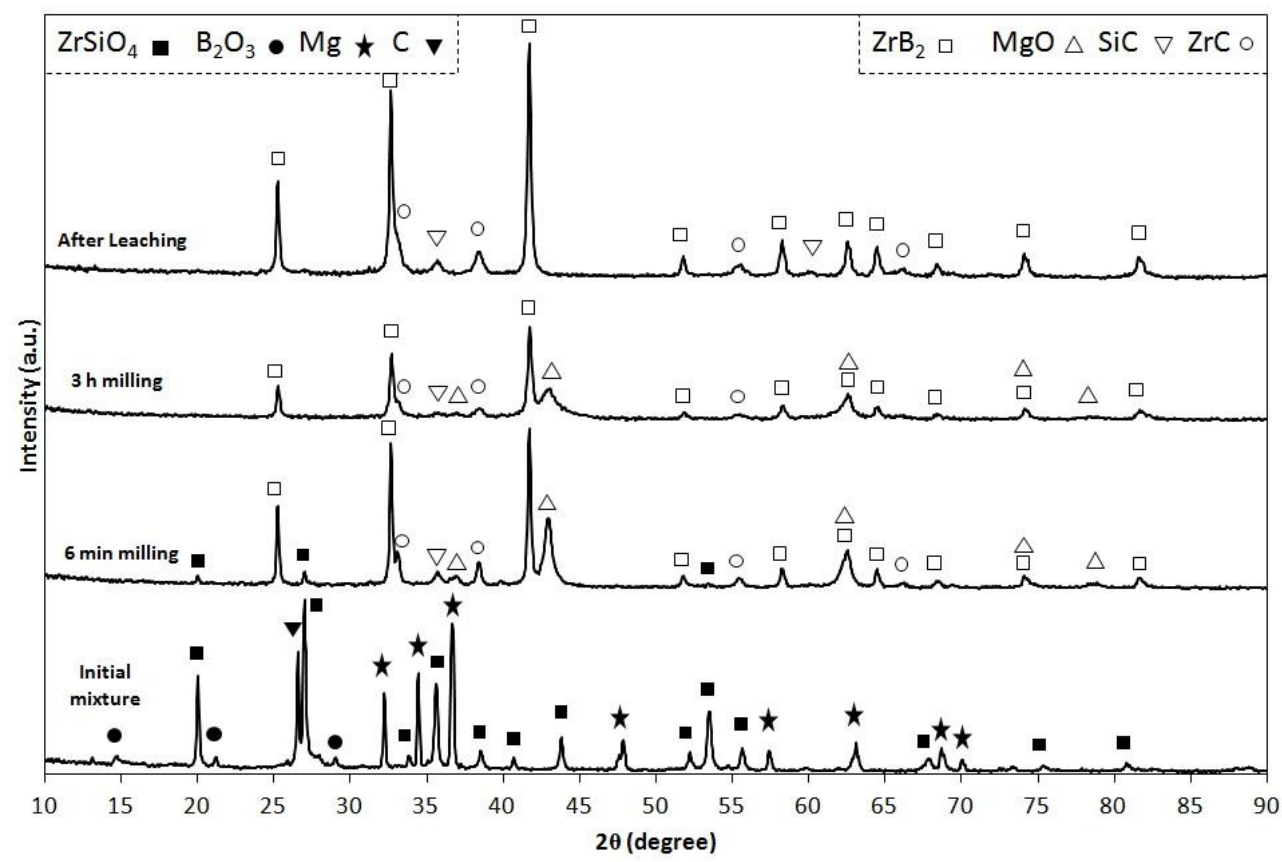

Fig. 4. X-ray diffraction patterns of as-blended, milled and leached samples of

$\mathrm{Mg} / \mathrm{ZrSiO}_{4} / \mathrm{B}_{2} \mathrm{O}_{3} / \mathrm{C}$ system.

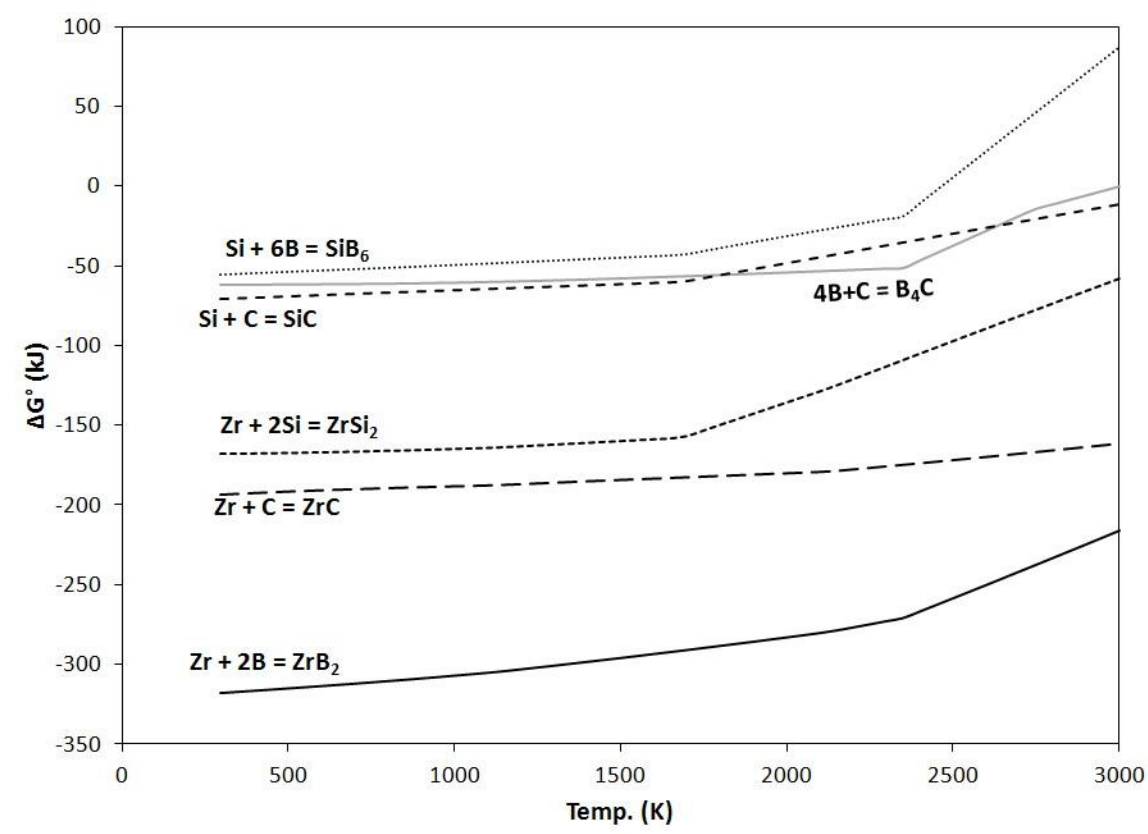

Fig. 5. The diagram of standard free energy of possible compounds between $\mathrm{Zr}, \mathrm{Si}, \mathrm{B}$ and $\mathrm{C}$ elements. 


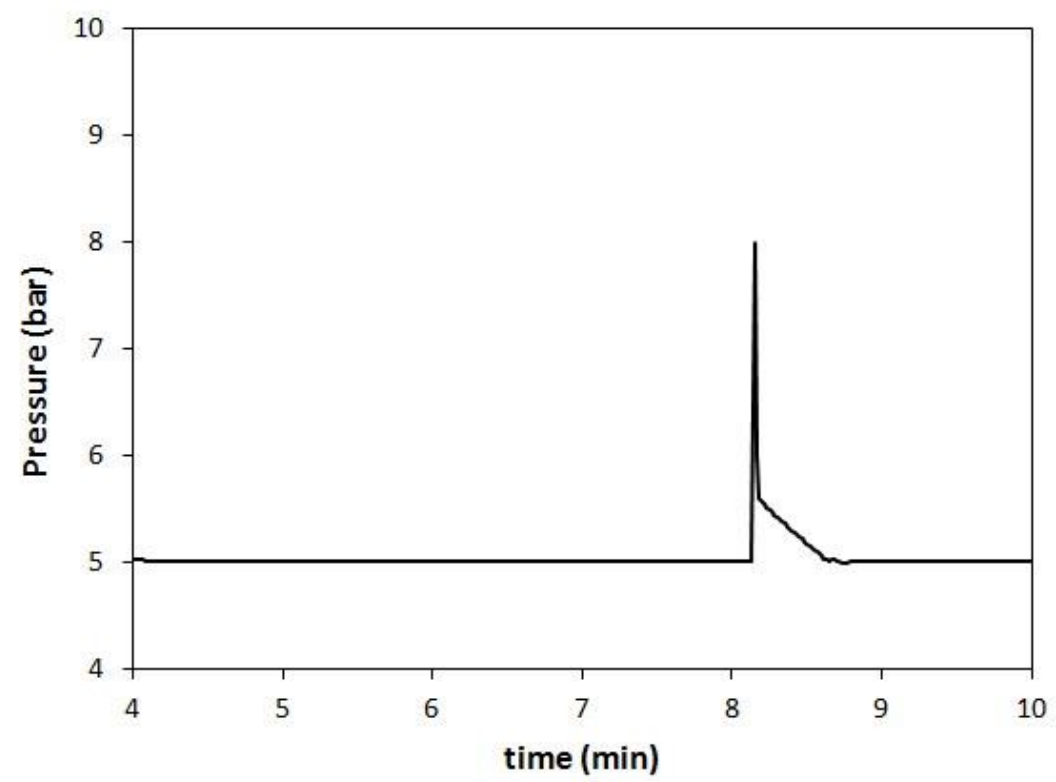

Fig. 6. Pressure inside the vial versus milling time for $\mathrm{Mg} / \mathrm{B}_{2} \mathrm{O}_{3}$ system.

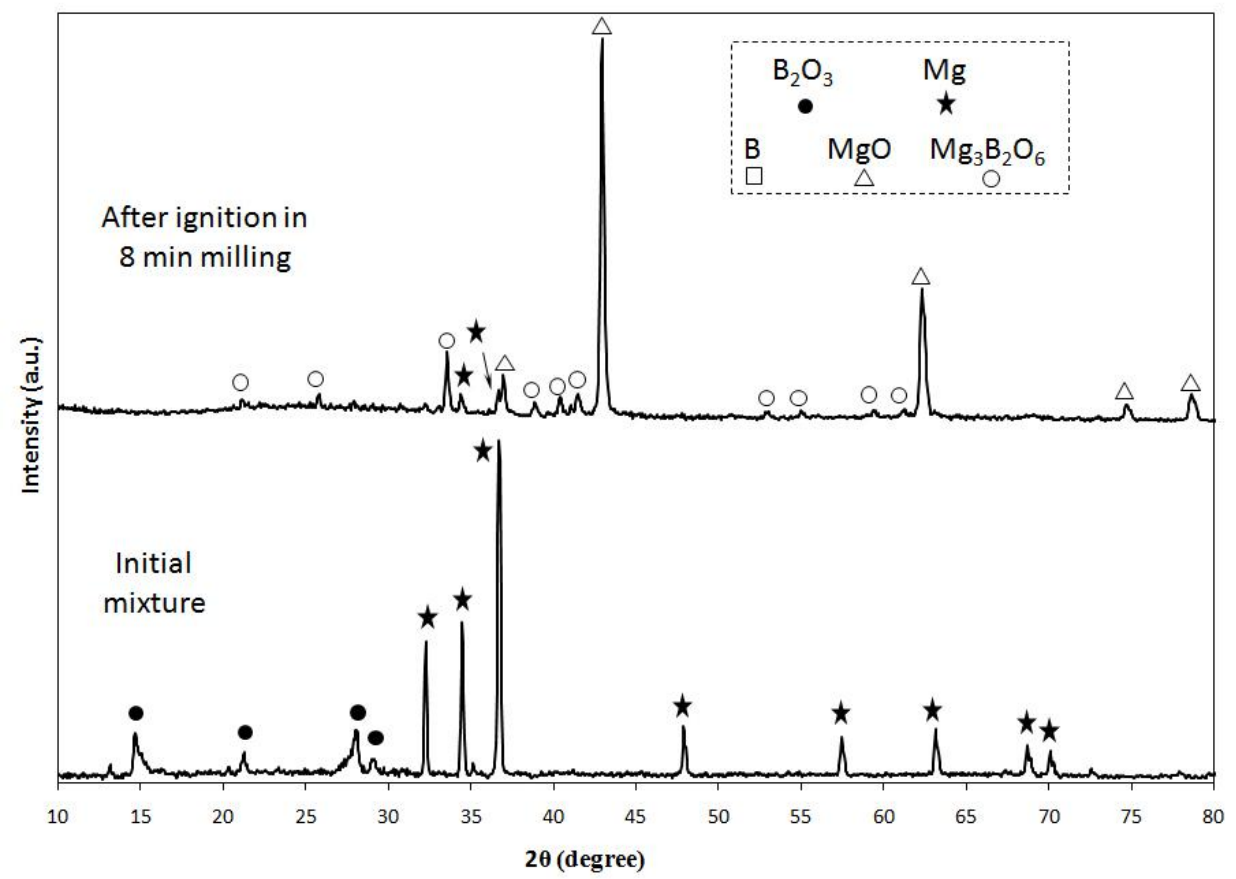

Fig. 7. X-ray diffraction patterns of initial and milled samples of $\mathrm{Mg} / \mathrm{B}_{2} \mathrm{O}_{3}$ system. 


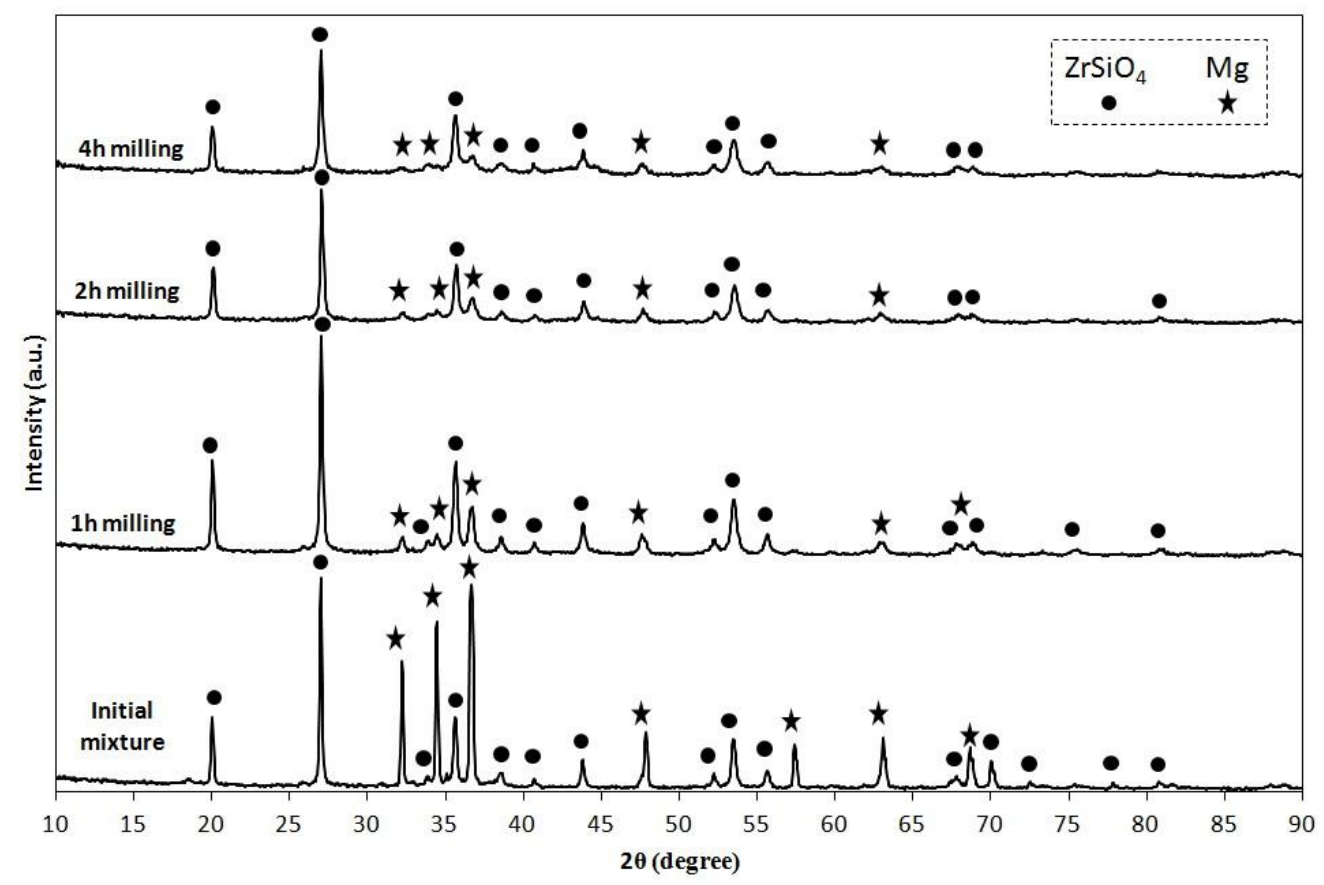

Fig. 8. X-ray diffraction patterns of initial and milled samples of $\mathrm{Mg} / \mathrm{ZrSiO}{ }_{4}$ system.
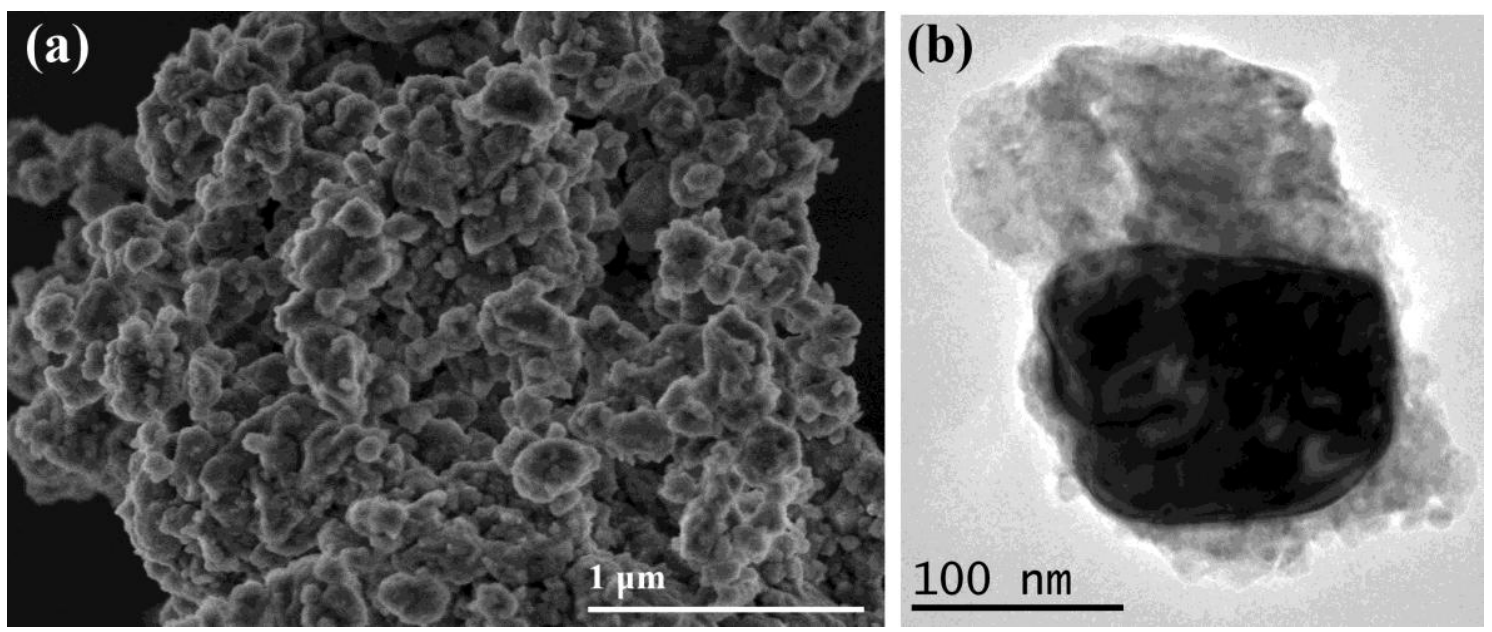

Fig. 9. Electron micrographs of $\mathrm{Mg} / \mathrm{ZrSiO}_{4} / \mathrm{B}_{2} \mathrm{O}_{3} / \mathrm{C}$ system after $3 \mathrm{~h}$ milling, (a) $\mathrm{SEM}$ and (b)

TEM images. 